\title{
Hubungan indeks massa tubuh (IMT) awal kehamilan dengan luaran maternal neonatal
}

\author{
${ }^{1}$ Rut C. F. Weku \\ ${ }^{2}$ John J. E. Wantania \\ ${ }^{2}$ Joice M. M. Sondakh
}

\author{
${ }^{1}$ Kandidat Skripsi Fakultas Kedokteran Universitas Manado \\ ${ }^{2}$ Bagian Obstetri dan Ginekologi Fakultas Kedokteran Universitas Sam Ratulangi \\ RSUP Prof. Dr. R. D. Kandou Manado \\ Email: Rutchristinferonichaweku76@yahoo.com
}

\begin{abstract}
Maternal nutritional status is very important for the outcomes of pregnancy. The best indicator for measuring the nutritional status is Body Mass Index (BMI). Abnormal BMI in early pregnancy is associated with various complications for the mother as well as the baby. This study was aimed to obtain the relationship between BMI in early pregnancy and maternal and neonatal outcomes. This was a retrospective analytical study with a cross sectional study. The results showed that there was a siginificant relationship between BMI in early pregnancy and blood pressure $(\mathrm{p}=0.049)$, but there was no significant relationship between BMI in early pregnancy and mode of delivery $(\mathrm{p}=0.067)$, birth $(\mathrm{p}=0.100)$, infant mortality (0.377), and APGAR score $(\mathrm{p}=0.100)$. Conclusion: Pregnant woman with BMI $\geq 25 \mathrm{~kg} / \mathrm{m}^{2}$ had a risk of hypertension in pregnancy and a sectio caesarea in delivery; and the baby showed a tendency of low birth weight, risk to death, and asphyxia.
\end{abstract}

Keywords: BMI, pregnancy and maternal neonatal outcomes

\begin{abstract}
Abstrak: Status gizi ibu sangat penting terhadap luaran kehamilan. Indikator untuk mengukur status gizi ialah Indeks Massa Tubuh (IMT). Ibu dengan IMT awal kehamilan yang tidak dalam batas normal berkaitan dengan berbagai komplikasi baik terhadap ibu maupun bayi. Penelitian ini bertujuan untuk mengetahui hubungan antara IMT awal kehamilan dengan luaran maternal neonatal. Jenis penelitian ialah analitik-retrospektif dengan desain potong lintang. Hasil penelitian mendapatkan bahwa IMT awal kehamilan berhubungan bermakna dengan tekanan darah $(p=0,049)$, tetapi tidak ditemukan hubungan bermakna antara IMT awal kehamilan dengan cara persalinan $(\mathrm{p}=0,069)$, berat badan lahir bayi $(\mathrm{p}=1,000)$, kematian bayi $(\mathrm{p}=0,377)$, dan APGAR skor $(\mathrm{p}=1,000)$. Simpulan: Ibu dengan IMT $\geq 25 \mathrm{~kg} / \mathrm{m}^{2}$ berisiko mengalami hipertensi dalam kehamilan, cenderung menjalani persalinan dengan seksio sesarea, dan bayinya cenderung memiliki berat badan lahir rendah, mengalami kematian, dan asfiksia.
\end{abstract}

Kata kunci: IMT, kehamilan dan luaran maternal neonatal.

Dimana pun di Indonesia setiap tiga menit, satu anak balita meninggal dunia, setiap jam, satu perempuan meninggal dunia ketika melahirkan atau karena sebab-sebab yang berhubungan dengan kehamilan. ${ }^{1}$ Berdasarkan SDKI (Survey Demografi dan Kesehatan Indonesia) tahun 2012 angka kematian naik menjadi 359 per 100.000 kelahiran hidup setelah mengalami penurunan pada tahun 1991 sampai tahun $2007 .^{2}$

Demikian juga untuk kematian neonatal berdasarkan profil kesehatan Indonesia tahun 2012, dikatakan bahwa kematian neonatal menyumbang lebih dari setengahnya kematian bayi $(59,4 \%)$, 
sedangkan jika dibandingkan dengan angka kematian balita, kematian neonatal menyumbang $47,5 \%$, dengan komplikasi neonatal yang menyebabkan kematian terbanyak adalah asfiksia, bayi berat lahir rendah, dan infeksi. ${ }^{3,4}$ luaran kehamilan tersebut dipengaruhi oleh beberapa hal, dan secara signifikan dipengaruhi oleh status gizi ibu. ${ }^{5,6}$

Ibu hamil dengan indeks massa tubuh (IMT) obesitas berkaitan dengan luaran kehamilan seperti preeklampsia/eklampsia, persalinan dengan induksi, mendapatkan bayi dengan makrosomia, mengalami seksio sesarea, dan perdarahan postpartum, ${ }^{7,8}$ Marchi et al. ${ }^{9}$ melaporkan beberapa risiko bagi ibu dengan obesitas, yaitu berisiko mengalami diabetes gestasional, hipertensi, seksio sesarea, mendapatkan bayi dengan kelahiran preterm, kematian, dan malformasi.

Demikian juga ibu dengan IMT underweight, berkaitan dengan luaran kehamilan yang merugikan. Penelitian yang dilakukan oleh Sebire et al. ${ }^{10}$ mendapatkan bahwa pada kelompok ibu dengan underweight lebih sering mengalami anemia, melahirkan prematur, dan memilik bayi dengan berat badan lahir rendah.

Penelitian ini bertujuan untuk mengetahui hubungan IMT awal kehamilan dengan luaran maternal neonatal di Puskesmas yang ada di Manado.

\section{METODE PENELITIAN}

Jenis penelitian ini ialah retrospektifanalitik dengan desain potong lintang. Penelitian ini dilakukan dengan mengambil sampel dari empat puskesmas di Manado, yaitu puskesmas Bahu, Ranotanaweru, Tuminting, dan Kombos. Penelitian ini dilakukan dari bulan September sampai November 2016.

Sampel penelitian ialah wanita yang melakukan kunjungan dengan usia kehamilan maksimal 16 minggu dan memiliki catatan persalinan di Puskesmas di Manado yang menjadi tempat penelitian.

Variabel bebas penelitian berupa IMT ibu dengan usia kehamilan maksimal 16 minggu. Variabel terikat ialah luaran maternal, yang dilihat berdasarkan tekanan darah dan cara persalinan, serta luaran neonatal berupa berat badan bayi, usia kehamilan, kematian bayi, kelainan kongenital, dan apgar skor. Pada penelitian ini, IMT ibu dibagi menjadi dua kelompok, yaitu IMT $<25 \mathrm{~kg} / \mathrm{m}^{2}$ dan IMT $\geq 25 \mathrm{~kg} / \mathrm{m}^{2}$.

Data diproses dengan menggunakan program SPSS 20. Analisis yang dilakukan ialah analisis univariat dan analisis bivariat, yaitu analisis chi-square/Fisher's exact test, dengan nilai signifikansi $p<0,05$.

\section{HASIL PENELITIAN}

Sampel yang didapatkan berjumlah 53 dengan usia berkisar 16-40 tahun. IMT sampel berkisar $17,7-36,98 \mathrm{~kg} / \mathrm{m}^{2}$ dengan rerata IMT $23,96 \mathrm{~kg} / \mathrm{m}^{2}$.

Tabel 1 menunjukkan bahwa sampel penelitian umumnya termasuk dalam kelompok IMT normal $\left(18,5-22,9 \mathrm{~kg} / \mathrm{m}^{2}\right)$ dan obese $\left(\geq 30 \mathrm{~kg} / \mathrm{m}^{2}\right)$.

Tabel 1. Data IMT sampel penelitian

\begin{tabular}{lcc}
\hline \multicolumn{1}{c}{ Klasifikasi IMT } & $\mathbf{N}$ & $(\boldsymbol{\%})$ \\
\hline Underweight & 3 & $(5,7)$ \\
Normal range & 20 & $(37.7)$ \\
Overweight at risk & 10 & $(18,9)$ \\
Obese & 20 & $(37,7)$ \\
& 53 & $(100)$ \\
\hline
\end{tabular}

Tabel 2 menunjukkan bahwa sebagian besar sampel $(94,3 \%)$ tidak memiliki riwayat hipertensi, dan menjalani persalinan pervaginam (83\%).

Tabel 2. Karakteristik sampel berdasarkan luaran maternal

\begin{tabular}{|c|c|c|c|}
\hline \multicolumn{2}{|c|}{ Luaran maternal } & $\mathbf{N}$ & $(\%)$ \\
\hline \multirow{2}{*}{$\begin{array}{c}\text { Tekanan } \\
\text { darah }\end{array}$} & Hipertensi & 3 & $(5,7)$ \\
\hline & $\begin{array}{l}\text { Tidak } \\
\text { Hipertensi }\end{array}$ & 50 & $(94,3)$ \\
\hline \multirow{2}{*}{$\begin{array}{c}\text { Cara } \\
\text { persalinan }\end{array}$} & Pervaginam & 44 & (83) \\
\hline & $\begin{array}{l}\text { Seksio } \\
\text { Sesarea }\end{array}$ & 9 & (17) \\
\hline
\end{tabular}

Tabel 3 menunjukkan bahwa umumnya luaran neonatal baik. Hanya dua sampel ditemukan dengan berat badan lahir 
rendah $<2500$ gram $(3,8 \%)$; kematian bayi didapatkan satu sampel $(1,9 \%)$; dan asfiksia didapatkan satu sampel $(1,9 \%)$.

Tabel 4 menunjukkan hasil analisis bivariat antara IMT dengan luaran maternal. Tabel tersebut menunjukkan bahwa ada hubungan yang signifikan antara IMT dengan tekanan darah $(p=0,049)$, tetapi tidak ditemukan hubungan yang signifikan antara IMT dengan cara persalinan.

Tabel 5 menunjukkan hasil analisis bivariat antara IMT dengan luaran neonatal. Tabel tersebut menunjukkan bahwa tidak ada hubungan yang sigifikan antara IMT dengan berat badan lahir, kematian bayi, dan apgar skor.

Tabel 3. Karakteristik sampel berdasarakan luaran neonatal

\begin{tabular}{cccc}
\hline \multicolumn{2}{c}{ Luaran Neonatal } & $\mathbf{N}$ & $\mathbf{( \% )}$ \\
\hline \multirow{2}{*}{ Berat badan lahir } & $<2500 \mathrm{~g}$ & 2 & $(3,8)$ \\
& $\geq 2500 \mathrm{~g}$ & 50 & $(96,2)$ \\
Usia kehamilan & $<37$ minggu & 0 & $(0)$ \\
& $\geq 37$ minggu & 53 & $(100)$ \\
Kematian bayi & Ada & 1 & $(1,9)$ \\
& Tidak ada & 52 & $(98,1)$ \\
Kelainan kongenital & Ada & 0 & $(0)$ \\
& Tidak ada & 52 & $(98,1)$ \\
Apgar skor & Tidak asfiksia & 51 & $(96,39)$ \\
& Asfiksia & 1 & $(1,9)$ \\
\hline
\end{tabular}

Tabel 4. Hubungan IMT dengan luaran maternal

\begin{tabular}{lccc}
\hline \multicolumn{1}{c}{ Kategori } & $\begin{array}{c}<\mathbf{2 5} \mathbf{~ K g} / \mathbf{m}^{\mathbf{2}} \\
\mathbf{N}(\boldsymbol{\%})\end{array}$ & $\begin{array}{c}\geq \mathbf{2 5} \mathbf{~ k g} / \mathbf{m}^{\mathbf{2}} \\
\mathbf{N}(\mathbf{\%})\end{array}$ & $\boldsymbol{p}$ \\
\hline Tidak hipertensi & $33(62,3)$ & $17(32,1)$ & $\mathbf{0 , 0 4 9}$ \\
Hipertensi & $0(0)$ & $3(5,7)$ & \\
Pervaginam & $30(56,6)$ & $14(26,3)$ & \multirow{2}{*}{0,067} \\
Seksio sesarea & $3(5,7)$ & $6(11,4)$ & \\
\hline
\end{tabular}

Tabel 5. Hubungan IMT dengan luaran neonatal

\begin{tabular}{lccc}
\hline \multicolumn{1}{c}{ Kategori } & $\begin{array}{ccc}<\mathbf{2 5} \mathbf{~ K g} / \mathbf{m}^{\mathbf{2}} \\
\mathbf{N}(\boldsymbol{\%})\end{array}$ & $\begin{array}{c}\mathbf{2 5} \mathbf{~ k g} / \mathbf{m}^{\mathbf{2}} \\
\mathbf{N}(\mathbf{\%})\end{array}$ & $\boldsymbol{P}$ \\
\hline$<2500 \mathrm{~g}$ & $1(1,9)$ & $1(1,9)$ & \multirow{2}{*}{1,000} \\
$\geq 2500 \mathrm{~g}$ & $32(60,4)$ & $18(33,9)$ & \\
Ada & $0(0)$ & $1(1,9)$ & 0,377 \\
Tidak ada & $33(62,3)$ & $19(35,8)$ & \\
Tidak asfiksia & $32(60,4)$ & $19(35,8)$ & 1,000 \\
Asfiksia & $0(0)$ & $1(1,9)$ & \\
\hline
\end{tabular}

\section{BAHASAN}

Pada penelitian ini didapatkan, bahwa IMT normal yang terbanyak sedangkan obese berjumlah 20 sampel $(37,7 \%)$, diikuti oleh IMT overweight at risk sebanyak 10 sampel (18,9\%). IMT underweight berjumlah paling sedikit yaitu tiga sampel $(5,7 \%)$. Pada penelitian ini, IMT dibagi menjadi dua kategori yaitu IMT $<25 \mathrm{~kg} / \mathrm{m}^{2}$ didapati sebanyak 33 sampel $(62,3 \%)$ dan IMT $\geq 25 \mathrm{~kg} / \mathrm{m}^{2}$ sebanyak 20 sampel $(37,7 \%)$. 
IMT $\geq 25 \mathrm{~kg} / \mathrm{m}^{2}$ berkaitan dengan beberapa luaran kehamilan yang merugikan. Seperti penelitian sebelumnya oleh Quedarusman ${ }^{11}$ mendapatkan bahwa ibu hamil dengan obesitas (IMT 25- $\geq 30$ $\mathrm{kg} / \mathrm{m}^{2}$ ) berisiko lima kali lebih besar untuk menderita preeklampsia. Penelitian yang dilakukan oleh Puspitasari et al. ${ }^{12}$ mendapatkan bahwa ibu dengan IMT >26 $\mathrm{kg} / \mathrm{m} 2$ cenderung mengalami hipertensi dalam kehamilan. Ekwendi. ${ }^{13}$ mendapatkan bawha sebanyak 50,22\% ibu hamil dengan obesitas (IMT $\geq 30 \mathrm{~kg} / \mathrm{m}^{2}$ ) menjalani seksio sesarea. Rahmani. ${ }^{14}$ mendapatkan bahwa ibu hamil dengan IMT overweight $0,91 \mathrm{kali}$ lebih berisiko mendapatkan bayi dengan BBLR (OR 0,91, CI 1,09-2,1) dan obese 1,59 kali lebih berisiko mendapatkan bayi dengan BBLR (OR 1,59, CI 1,30-4,51).

Sesuai dengan penelitian sekarang jika ditinjau dari luaran maternal didapatkan kejadian hipertensi sebanyak tiga sampel $(5,7 \%)$ ditemukan pada ibu dengan IMT $\geq 25 \mathrm{~kg} / \mathrm{m}^{2}$, persalinan seksio sebanyak sembilan sampel (17\%), enam sampel diantaranya $(11,7 \%)$ ditemukan pada ibu dengan IMT $\geq 25 \mathrm{~kg} / \mathrm{m}^{2}$. Demikian juga ditinjau dari luaran neonatal, ditemukan bahwa berat badan bayi $<2500$ g sebanyak dua sampel $(3,8 \%)$, satu di antaranya ditemukan pada ibu dengan IMT $\geq 25$ $\mathrm{kg} / \mathrm{m}^{2}$,; kematian bayi dan asfiksia masingmasing satu sampel $(1,9 \%)$ ditemukan pada ibu dengan $\mathrm{IMT} \geq 25 \mathrm{~kg} / \mathrm{m}^{2}$.

Dari hasil analisis bivariat, ditemukan terdapat hubungan bermakna antara IMT dengan hipertensi dalam kehamilan dengan nilai $p=0,049 \quad(p<0,05)$. Sesuai dengan penelitian sebelumnya oleh Puspitasari et al. ${ }^{12}$ yang juga mendapatkan adanya hubungan bermakna antara IMT dengan hipertensi dalam kehamilan tetapi sedikit berbeda dengan penelitian sekarang karena penelitian oleh Puspitasari et al, ${ }^{12}$ membagi IMT menjadi $>26 \mathrm{~kg} / \mathrm{m}^{2}$ dan $\leq 26 \mathrm{~kg} / \mathrm{m}^{2}$. Penelitian yang dilakukan oleh Quedarusman $^{11}$ dengan menggunakan metode penelitian kasus kontrol juga mendapatermaknakan hubungan antara IMT dengan preeklampsia, walaupun pada penelitian sekarang hanya memfokuskan pada kejadian hipertensi secara umum.

Dari hasil analisis bivariat, tidak ditemukan hubungan bermakna antara IMT awal kehamilan dengan cara persalinan $(p=0,067)$, dan APGAR skor $(p=1,000)$.

Penelitian sebelumnya yang dilakukan oleh Bharpoda et al. ${ }^{15}$ juga tidak menemukan hubungan IMT dengan cara persalinan. Bharpoda et al. ${ }^{15}$ menjelaskan bahwa hal ini dapat disebabkan oleh karena penelitiannya mengeksklusikan komplikasi kehamilan seperti diabetes gestasional dan preeklampsia. Pada penelitian sekarang tidak ditemukan hubungan antara IMT dengan cara persalinan, dapat disebabkan karena pada penelitian ini semua riwayat persalinan seksio sesarea diambil tanpa memperhitungkan alasan dilakukan seksio sesarea. Persalian seksio sesarea pada penelitian ini didominasi oleh sampel yang tidak memiliki riwayat komplikasi hipertensi. Bharpoda et al. ${ }^{15}$ juga tidak menemukan hubungan antara IMT dengan APGAR skor, yang berbeda dengan penelitian yang dilakukan oleh Rahmani ${ }^{14}$ yang menemukan hubungan antara IMT dengan APGAR skor. Perbedaan ini disebabkan oleh karena pada penelitiannya Rahmani $^{14}$ menginklusikan komplikasi kehamilan seperti hipertensi dan diabetes gestasional, sedangkan Bharpoda et al. ${ }^{15}$ mengeksklusikan komplikasi-komplikasi tersebut. Demikian juga pada penelitian sekarang tidak didapatkan hubungan antara IMT dengan APGAR skor yang dapat disebabkan karena pada penelitian sekarang hanya menemukan satu sampel dengan asfiksia dan tidak ditemukan pada ibu dengan komplikasi hipertensi.

Pada hipertensi dalam kehamilan terajadi kegagalan remodeling arteri spiralis, yang ditandai oleh tidak adanya invasi dari sel-sel trofoblas pada lapisan otot arteri spiralis dan jaringan matriks sekitarnya. Akibatnya lapisan otot arteri spiralis menjadi tetap kaku dan keras, sehingga arteri spiralis yang menjamin aliran darah uteroplasenta relatif mengalami vasokonstriksi, menyebabkan aliran darah uteroplasenta menurun, dan terjadilah hipoksia dan iskemia plasenta. ${ }^{16}$ Hal ini 
menjelaskan bahwa komplikasi-komplikasi, khususnya hipertensi dalam kehamilan dapat mempengaruhi APGAR skor.

Dari hasil analisis bivariat, tidak ditemukan hubungan bermakna antara IMT awal kehamilan dengan berat badan lahir $(p=1,000)$, yang berbeda dengan penelitian sebelumnya oleh Sari ${ }^{17}$ yang menemukan terdapat hubungan antara IMT dengan $\operatorname{BBLR}(<2500 \mathrm{~g})$. Pada penelitiannya Sari ${ }^{17}$ menyimpulkan bahwa makin rendah IMT ibu makin berisiko mendapatkan bayi dengan BBLR. Pada penelitian sekarang tidak didapatkan hubungan antara IMT dengan berat badan lahir disebabkan karena hanya ditemukan dua sampel bayi dengan berat badan bayi <2500 gram, dan tidak ditemukan pada ibu dengan IMT underweight.

Keterbatasan penelitian ialah jumlah sampel terlalu sedikit dan umumnya memiliki hasil yang konstan sehingga tidak semua variabel terikat dapat dianalisis. Pada variabel yang dianalisis, kemungkinan terdapat bias, karena jumlah kasus yang terlalu sedikit. Tidak dilakukan analisis ratio prevalence untuk melihat berapa besar nilai risiko karena jumlah kasus yang terlalu sedikit

\section{SIMPULAN}

Dari hasil penelitian dan bahasan dapat disimpulkan bahwa terdapat hubungan bermakna antara IMT awal kehamilan dengan hipertensi dalam kehamilan, tetapi tidak terdapat hubungan bermakna antara IMT awal kehamilan dengan cara persalinan

Tidak terdapat hubungan bermakna antara IMT awal kehamilan dengan luaran neonatal, yaitu berat badan lahir, kematian bayi, dan APGAR skor.

\section{SARAN}

Bagi tenaga kesehatan agar menginformasikan pentingnya IMT normal sebelum hamil.

Bagi peneliti lanjut, perlu dilakukan dengan jumlah sampel yang lebih besar dan variabel terikat yang terpisah.

\section{DAFTAR PUSTAKA}

1. UNICEF Indonesia. Ringkasan Kajian: Kesehatan ibu \& anak. Unicef Org [internet]. 2012 October; 6(1). Available from: http://www.unicef.org/indonesia/id/A5 _B_Ringkasan_Kajian_Kesehatan_R EV.pdf

2. Kementerian Kesehatan RI. Infodatin ibu [internet]. 2014;8(2). Available from: https://www.google.co.id/url?sa=t\&rct $=\mathrm{j} \& \mathrm{q}=\&$ esrc $=\mathrm{s} \&$ source $=$ web $\& \mathrm{~cd}=1 \& \mathrm{c}$ $\mathrm{ad}=\mathrm{rja} \& u a c t=8 \& v e d=0$ ahUKEwjBu5v qtePOAhUDwI8KHWteBpwQFggcM AA\&url=http $\% 3 \mathrm{~A} \% 2 \mathrm{~F} \% 2 \mathrm{Fwww}$.depk es.go.id\%2Fdownload.php\%3Ffile\%3 Ddownload\%2Fpusdatin\%2Finfodatin $\% 2$ Finfodatinibu.pdf\&usg=AFQjCNFtB3UlIKvWh QNW8moSJqabIfojjQ\&sig2=NQEgfH NhDeOylrwZtAtk0A

3. Kementerian Kesehatan Republik Indonesia. Profil kesehatan Indonesia 2012. 2013 July [cited 2015 Aug 16]. Available from

:http://www.depkes.go.id/resources/do wnload/pusdatin/profil-kesehatanindonesia/profil-kesehatan-indonesia2012.pdf

4. Denisson FC, Norwood P, Bhattacharya S, Duffy A, Mahmood T, Morris C, et al. Association between maternal body mass index during pregnancy, shortterm morbidity, and increased health service costs: a population-based study. BJOG. 2013;121:73.

5. Tumundo M, Tendean H, Suparman E. Kematian perinatal di BLU Prof. Dr. R. D. Kandou Manado. Portal Garuda [internet]. 2013; 5(2,3). Available from: http://download.portalgaruda.org/article .php?article $=157379 \&$ val $=1008 \&$ title $=$ KEMATIAN\%20PERINATAL\%20DI \%20BLU\%20RSU\%20PROF.\%20DR. $\% 20$ R.\%20D.\%20KANDOU\%20MA NADO

6. Mulyaningrum S. Faktor-faktor yang berhubungan dengan kurang energi kronis. Wordpress [Internet]. 2009; 25(1,2,3). Available from: https://andigayo.files.wordpress.com/20 13/03/file.pdf

7. Sativa G, Cahyani RD. Pengaruh indeks massa tubuh wanita pada saat persalinan terhadap keluaran maternal 
dan perinatal di RSUP Dr. Kariadi periode tahun 2010. Core. 2011;26:9. Available from: https: //core.ac.uk/download/files/379/117317 21.pdf

8. Yazdani S, Yosofniyapasha Y, Nasab BH, Mojaveri MH, Bouzan Z. Effect of maternal body mass index on pregnancy outcome and newborn weight. Biomed central Ltd [internet]. 2012 january. Available from: http://www.ncbi.nlm.nih.gov/pmc/articl es/PMC3292487/

9. Marchi J, Berg M, Dencker A, Olander EK, Begley C. Risks associated with obesity in pregnancy, for the mother and baby: a systematic review of review. Online Library [internet]. 2015 May; 18(16). Available from: http://onlinelibrary.wiley.com/doi/10.1 111/obr.12288/pdf

10. Sebire NJ, Jolly M, Harris J, Regan L, Robinson S. Is maternal underweight really a risk factor for adverse pregnancy outcome? A population based study in London. British Journal of Obstetrics and Gynaecology. $2001 ; 7(1,3)$.

11. Quedarusman H, Wantania J, Kaeng JJ. Hubungan indeks massa tubuh ibu dan peningkatan berat badan saat kehamilan dengan preeklampsia. ejournal Unsrat [internet]. 2013;1(1-7). Available from: http: //ejournal.unsrat.ac.id/ index.php/ ebiomedik/article/view/4363/3892

12. Puspitasari DR, Setyabudi MT, Rohmani
A. hubungan usia, graviditas dan indeks massa tubuh dengan kejadian hipertensi dalam kehamilan. Jurnal Kedokternan Muhammadiyah [internet]. 2015;2:1-5.

13. Ekwendi AS, Mewengkang ME, Wagey FMM. Perbandingan persalinan seksio sesarea dan pervaginam pada wanita hamil dengan obesitas. Journal eCl. 2016;4(1).

14. Rahmani E, Ahmadi S, Motamed N, Foroozanfar S. Body mass index before and after pregnancy associated with maternal and neonatal complications. Crescent Journal of Medical and Biological Science [internet]. 2016 March:3(1-5). Available from: http://www.cjmb.org/PDF/CJMB-3123.pdf

15. Bharpoda NY, Leuva BR, Patel U, Patel SG, Srikranthi, Kothari A. Study of the effect of maternal body mass index (BMI) on perinatal outcome. IAIM. 2016;3(2):74-8.

16. Prawirohardjo S. Ilmu Kebidanan (4th ed). Jakarta: Bina Pustaka Sarwono Prawirohardjo, 2014.

17. Sari A, Nor S, Desi. Hubungan indeks massa tubuh pada awal kehamilan dengan berat badan lahir di wilayah kerja Puskesmas Sungai Jingah. Ejournal Akibid Sari Mulia [internet]. 2013 Des. Available from: http://ejurnal. akbidsarimulia.ac.id/downlot.php?file= Anggrita\%20Sari,\%20SSiT,M.Pd.,M.K es.pdf 